Formatif: Jurnal Ilmiah Pendidikan MIPA

Vol. 8, No. 1, April 2018, pp. 7-16

p-ISSN: 2088-351X

e-ISSN: 2502-5457

DOI: http://dx.doi.org/10.30998/formatif.v8i1.2303

\title{
Application of Blended Learning with Edmodo Application Based on PDEODE Learning Strategy to Increase Student Learning Achievement
}

\author{
Penerapan Blended Learning dengan Aplikasi Edmodo Berbasis Strategi \\ Pembelajaran PDEODE Untuk Meningkatkan Prestasi Belajar Siswa
}

Noor Emmy Ekawati

MTs Negeri Magelang

\begin{abstract}
Received: February 25, 2018

Revised: March 23, 2018

Accepted: April 4, 2018

This study aims to determine the application of blended learning with edmodo application based on PDEODE learning strategy (Predict-DiscussExplain-Observe-Discuss-Explain). The process of teaching science teaching in class VIII MTs Negeri Magelang is still running monoton that is still using conventional method, so that students are more passive. Utilization of technology and the internet is less effective, whereas facilities and infrastructure that exist in school is complete. The type of this research is Classroom Action Research (PTK) which is carried out in 4 stages, they are plan, act, observe, and reflect. Data analysis technique using gain standar to know student achievement before and after action. The results showed that the application of blended learning with edmodo application based on PDEODE learning strategy can improve student achievement of VIIIF grade MTs N Magelang. This is evidenced by the percentage of students' learning mastery of pre-cycle to cycle 1 increased $31 \%$, increase from cycle I to cycle II by $62 \%$, and increase from pre-cycle to cycle II by $93 \%$.
\end{abstract}

Keywords: Blended Learning, PDEODE, Edmodo, Learning Achievement.

(*) Corresponding Author: $\quad$ Email: nooremmy_e1@ymail.com

How to Cite: Ekawati, N. E. (2018). Application of blended learning with edmodo application based on PDEODE learning strategy to increase student learning achievement. Formatif: Jurnal Ilmiah Pendidikan MIPA, 8 (1): 7-16. http://dx.doi.org/10.30998/formatif.v8i1.2303

\section{PENDAHULUAN}

Fisika merupakan bagian dari mata pelajaran IPA. Ilmu Fisika mencakup pengetahuan fisika yang berupa fakta, teori, prinsip dan hukum berdasarkan temuan saintis dan kerja ilmiah. Namun sampai saat ini masih banyak siswa yang menjadikan fisika sebagai mata pelajaran yang sulit dan menakutkan. MTs Negeri Magelang merupakan sekolah yang berlokasi di kota Magelang. Pembelajaran yang dilakukan oleh guru di sekolah tersebut mayoritas masih menggunakan model konvensional yaitu dengan metode ceramah. Penggunaan media pembelajaran atau alat peraga belum banyak dilakukan oleh guru. Dikalangan siswa, banyak yang beranggapan bahwa belajar adalah suatu aktivitas yang tidak menyenangkan, mereka datang, duduk berjam-jam mencurahkan perhatian dan pikiran terhadap suatu pokok bahasan yang disampaikan oleh guru. Karena pembelajaran yang monoton dan tidak menyenangkan inilah maka sering dijumpai siswa yang bosan mengikuti pembelajaran IPA Fisika. Terlebih materi fisika harus menuntut siswa paham persamaan-persamaan atau rumus-rumus fisika, yang menyebabkan siswa malas untuk belajar. Tidak bisa dipungkiri bahwa perhatian siswa 


\section{Formatif: Jurnal Ilmiah Pendidikan MIPA}

Vol. 8, No. 1, April 2018, pp. 7-16

p-ISSN: 2088-351X

e-ISSN: 2502-5457

DOI: http://dx.doi.org/10.30998/formatif.v8i1.2303

bergantung pada menarik dan tidaknya proses pembelajaran yang berlangsung. Siswa jadi kurang termotivasi dalam belajar fisika. Karena motivasi siswa rendah akan mempengaruhi hail belajar siswa juga rendah.

Dengan demikian, guru perlu menggunakan model pembelajaran yang dapat meningkatkan keaktifan, mengembangkan kondisi belajar yang relevan agar tercipta suasana belajar secara wajar dengan penuh kegembiraan, dan mengadakan pembatasan positif terhadap dirinya sebagai seorang guru. Strategi pembelajaran PDEODE (predictdiscus-explain-observe-discuss-explain) mampu melatih siswa untuk membangun konsep-konsep yang ilmiah. Hal ini dikarenakan siswa dapat berpikir mandiri, siswa aktif berbicara atau menulis, secara interaktif mengkomunikasikan buah pikiran kepada siswa yang lain, melakukan dan mengamati percobaan secara langsung, mengklarifikasi, mempertahankan, mengembangkan, dan menjelaskan pikiran siswa (Wulandari et al, 2015).

Perkembangan teknologi informasi yang sangat pesat saat ini tidak bisa dihindari pengaruhnya terhadap dunia pendidikan. Perkembangan teknologi informasi dan komunikasi ini berdampak pada penggunaan alat-alat bantu mengajar seperti komputer dan internet, seperti contohnya e-learning. E-learning merupakan proses pembelajaran secara elektronik. Namun pembelajaran bukan semata bertumpu pada teknologi, sebab pembelajaran pada hakikatnya lebih pada proses interaksi antara guru, siswa, dan sumber belajar. Meskipun $e$-learning bisa digunakan secara mandiri oleh siswa, namun eksistensi guru menjadi sangat berarti sebagai orang dewasa yang berfungsi memberi dukungan dan mendampingi siswa dalam proses pembelajaran. Dengan kata lain, proses tatap muka menjadi hal yang penting dan tidak boleh ditinggalkan dalam pembelajaran. Sehingga dengan menggabungkan antara pembelajaran e-learning dan tatap muka maka memungkinkan tercapainya pembelajaran yang efektif. Penggabungan beberapa model pembelajaran inilah yang disebut dengan Blended learning.

Pembelajaran blended learning merupakan jenis pembelajaran yang menggabungkan pengajaran klasikal (face to face) dengan pengajaran online (Sari, 2013). Blended learning dalam penelitian ini dianggap sebagai interaksi pembelajaran tatap muka dengan pembelajaran dengan pendekatan online. Pembelajaran online dalam penelitian ini dilakukan dengan aplikasi edmodo. Edmodo merupakan jejaring sosial untuk pembelajaran berbasis learning management system (LMS). Edmodo memberikan fasilitas bagi guru, murid tempat yang aman untuk berkomunikasi, berkolaborasi, berbagi konten dan aplikasi pembelajaran, pekerjaan rumah bagi siswa, diskusi dalam kelas virtual, ulangan secara online, penyediaan nilai, dan lain sebagainya. Menurut Dharmawati (2017), Edmodo sangat komprehensif sebagai sebuah course management system seperti Moodle, bedanya adalah aksesnya lebih cepat dan lebih mudah menggunakannya. Edmodo memiliki tiga fungsi dalam proses pembelajaran, yakni fungsi pengganti, pendamping, dan pelengkap (Ainiyah \& Puspasari, 2015).

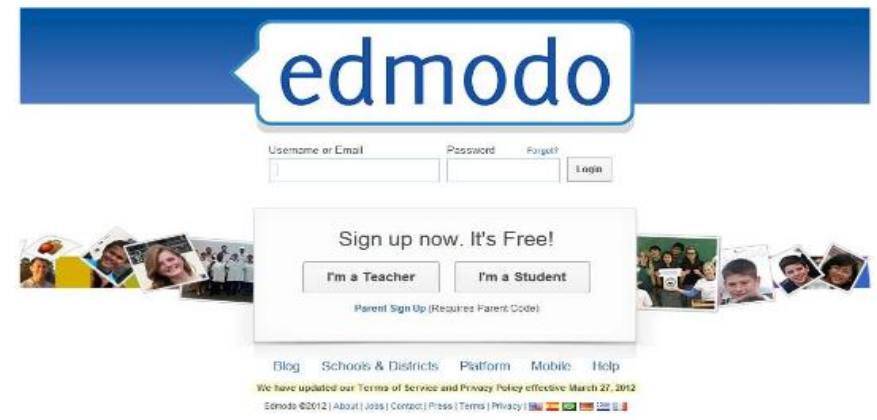

Gambar 1. Tampilan halaman depan edmodo 
Formatif: Jurnal Ilmiah Pendidikan MIPA

Vol. 8, No. 1, April 2018, pp. 7-16

p-ISSN: 2088-351X

e-ISSN: 2502-5457

DOI: http://dx.doi.org/10.30998/formatif.v8i1.2303

Berdasarkan latar belakang yang telah diuraikan, peneliti menerapkan blended learning dengan aplikasi Edmodo berbasis strategi PDEODE dalam pembelajaran di kelas. Diharapkan dengan diterapkannya pembelajaran blended learning dengan aplikasi Edmodo berbasis strategi PDEODE, maka dapat meningkatkan prestasi belajar siswa dalam pelajaran IPA Fisika kelas VIII MTs N Magelang.

\section{METODE}

Penelitian ini menggunakan rancangan penelitian tindakan kelas yang terfokus dalam kegiatan di kelas sehingga penelitiannya berupa Penelitian Tindakan Kelas (PTK). PTK adalah penelitian tindakan yang dilaksanakan di dalam kelas ketika pembelajaran berlangsung (Warso, 2013). Subjek dalam penelitian ini adalah seluruh siswa kelas VIII F MTs Negeri Magelang tahun ajaran 2015/2016 yang berjumlah 29 siswa, yang terdiri dari 17 siswa laki-laki dan 12 siswa perempuan.

Instrumen dalam penelitian ini yaitu lembar pelaksanaan pembelajaran dan lembar soal tes evalausi. Langkah-langkah penelitian ini terdiri dari 4 tahap yaitu tahap perencanaan (plan), tahap tindakan (act), tahap observasi (observe) dan tahap refleksi (reflect). Tahap perencanaan dilakukan agar pelaksanaan penelitian dapat berjalan sesuai harapan. Kegiatan dilakukan pada tahap ini meliputi penyusunan Rencana Pelaksanaan pembelajaran (RPP), lembar kerja siswa, soal pretest, pembentukan kelompok belajar siswa, menyiapkan alat praktikum siswa, lembar observasi pelaksanaan pembelajaran, soal posttest. Dalam penelitian ini, kelompok dibentuk secara heterogen berdasarkan jenis kelamin dan prestasi belajar siswa.

Tahap tindakan dalam penelitian ini yaitu berupa penerapan blended learning dengan aplikasi Edmodo berbasis strategi pembelajaran PDEODE. Adapun secara garis besar, tahap-tahap pelaksanaannya seperti digambarkan dalam gambar 2. 1) Predict, guru memberikan permasalahan (soal) dengan Edmodo, kemudian siswa melakukan prediksi penyelesaian masalah terhadap suatu peristiwa cahaya; 2) discuss 1 , siswa berdiskusi dalam kelompoknya masing-masing dengan e-learning di edmodo (note) terkait prediksi solusi awal tentang permasalahan (soal) yang diberikan oleh guru, sekaligus guru memberikan pretest dalam penelitian ini; 3) Explain 1, pada kegiatan explain ini dilakukan secara tatap muka, siswa mengemukakan pendapat kelompok berdasarkan diskusi kelompok pertama di Edmodo; 4) Observe, pada langkah ini dilakukan dengan tatap muka, siswa melakukan praktikum di laboratorium sesuai dengan permasalahan yang diberikan oleh guru untuk mengamati kemungkinan-kemungkinan kejadian yang mungkin bisa digunakan dalam mengambil kesimpulan. Guru membimbing siswa untuk membuat pengamatan yang relevan dengan konsep yang tepat; 5) Discuss 2, siswa mendiskusikan hasil praktikum bersama teman sekelompoknya dilakukan dengan tatap muka di kelas; 6) Explain 2, siswa melakukan presentasi di depan kelas tiap kelompok berdasarkan hasil praktikum dan diskusi kelompok. Setelah selesai presentasi siswa mengerjakan soal evaluasi (posttest) untuk mengetahui prestasi belajar siswa terhadap pemahaman konsep cahaya.

Dalam penelitian ini analisis data meliputi data hasil observasi pelaksanaan pembelajaran melalui Blended Learning dengan aplikasi Edmodo berbasis strategi pembelajaran PDEODE, data pretest dan postest siklus. Prestasi belajar siswa dinilai melalui tes evaluasi dengan persamaan menghitung nilai rata-rata kelas. 
Formatif: Jurnal Ilmiah Pendidikan MIPA

Vol. 8, No. 1, April 2018, pp. 7-16

p-ISSN: 2088-351X

e-ISSN: 2502-5457

DOI: http://dx.doi.org/10.30998/formatif.v8i1.2303

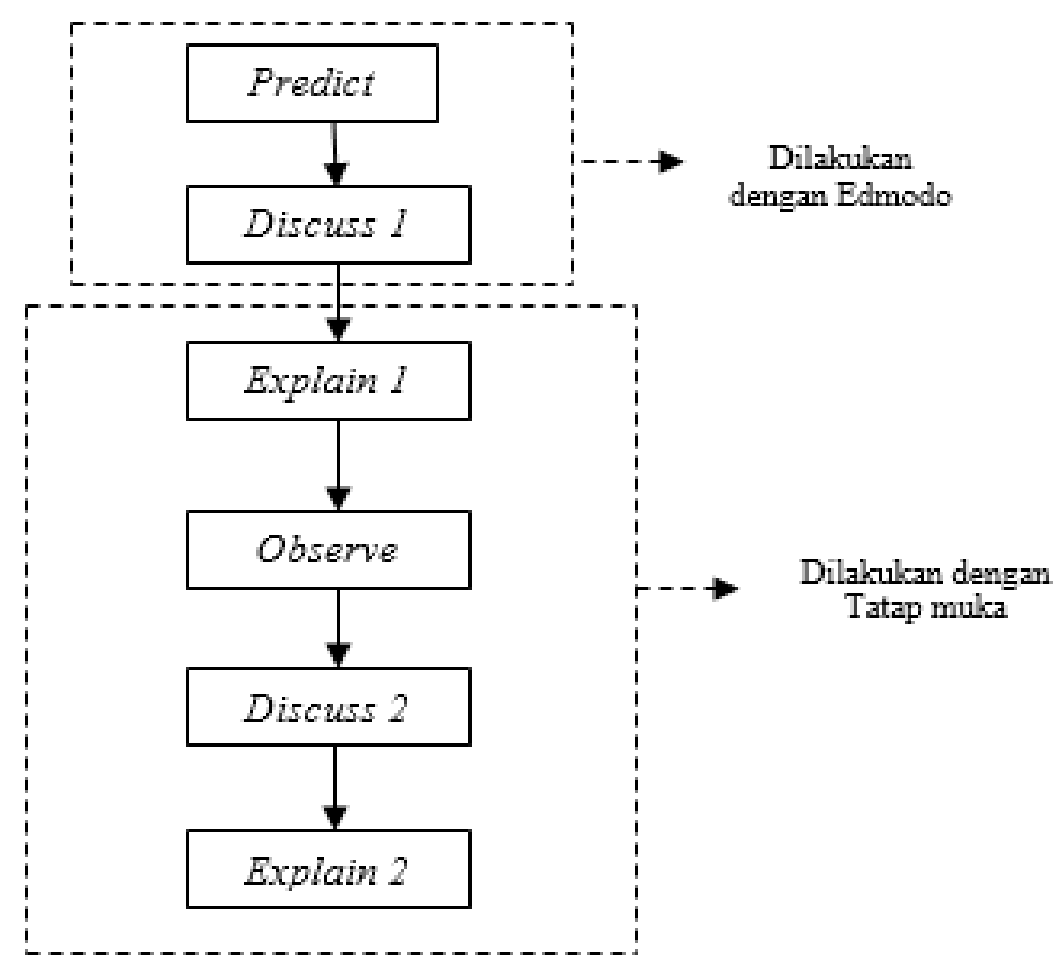

Gambar 2. Tahapan pelaksanaan PDEODE dengan blended learning edmodo

Untuk mengetahui ketuntasan belajar peserta didik digunakan rumus:

$$
K B=\frac{T}{T t} \times 100 \%
$$

Keterangan:

$K B$ : Ketuntasan belajar

$T$ : Jumlah peserta didik yang tuntas belajar

$T t$ : Jumlah seluruh peserta didik

Tabel 1. Kiteria ketuntasan belajar peserta didik

\begin{tabular}{cc}
\hline Interval Skor & Kategori \\
\hline Nilai $\leq 75$ & peserta didik tidak tuntas belajar \\
Nilai $\geq 75$ & peserta didik tuntas belajar \\
\hline
\end{tabular}

Data yang dipakai untuk melihat peningkatan prestasi belajar adalah data hasil pretest dan posttest. Selanjutnya hasil tes tersebut dihitung rata - ratanya dengan menggunakan rumus Gain standar (Sugiyono, 2011).

$$
\text { Gain Standar }=\frac{\text { skorpostes }- \text { skorpretes }}{\text { skormaksimem }- \text { skorpretes }}
$$

Kriteria perolehan skor dapat dilihat pada tabel 2: 
Formatif: Jurnal Ilmiah Pendidikan MIPA

Vol. 8, No. 1, April 2018, pp. 7-16

p-ISSN: 2088-351X

e-ISSN: 2502-5457

DOI: http://dx.doi.org/10.30998/formatif.v8i1.2303

Tabel 2. Kategori Perolehan Skor Gain Standar

\begin{tabular}{cc}
\hline Batasan & Kategori \\
\hline $\mathrm{g}>0,7$ & Tinggi \\
$0,3<\mathrm{g} \leq 0,7$ & Sedang \\
$\mathrm{g} \leq 0,3$ & Rendah \\
\hline
\end{tabular}

\section{HASIL DAN PEMBAHASAN}

\section{Hasil}

Penilaian prestasi belajar siswa dilihat dari aspek kognitif setelah pembelajaran siklus I selesai. Evaluasi dilakukan dengan menggunakan edmodo. Pada evaluasi ini siswa diberi waktu 60 menit untuk mengerjakan secara online. Hasil nilai pada siklus I dapat dilihat pada tabel 3.

Tabel 3. Hasil prestasi belajar siklus I

\begin{tabular}{lc}
\hline \multicolumn{1}{c}{ Deskripsi prestasi belajar siswa } & Siklus I \\
\hline Nilai rata-rata & 65 \\
Nilai maksimal & 93 \\
Nilai minimal & 33 \\
Jumlah siswa yang tuntas & 11 \\
Jumlah siswa yang tidak tuntas & 18 \\
Persentase ketuntasan belajar & $38 \%$ \\
Persentase ketidaktuntasan belajar & $62 \%$ \\
\hline
\end{tabular}

Dari hasil tersebut diperoleh persentase ketuntasan belajar IPA sebesar 38\%. Hal ini belum sesuai dengan taraf ketuntasan belajar yaitu $>85 \%$. Nilai rata-rata siswa pada siklus I juga belum sesuai dengan batas tuntas KKM yang seharusnya 75 . Oleh karena itu perlu dilakukan refleksi dan tindakan pada siklus II.

Evaluasi atau postest siswa pada siklus II dilaksanakan setelah pembelajaran siklus II selesai. Tes berupa tes tertulis dengan jenis tes berupa pilihan ganda sebanyak 30 butir soal. Setelah dianalisis diperoleh hasil prestasi belajar siswa yang ditunjukkan pada tabel 4.

Tabel 4. Hasil prestasi belajar siklus II

\begin{tabular}{lc}
\hline \multicolumn{1}{c}{ Deskripsi prestasi belajar siswa } & Siklus II \\
\hline Nilai rata-rata & 88 \\
Nilai maksimal & 97 \\
Nilai minimal & 77 \\
Jumlah siswa yang tuntas & 29 siswa \\
Jumlah siswa yang tidak tuntas & 0 \\
Persentase ketuntasan belajar & $100 \%$ \\
Persentase ketidaktuntasan belajar & 0 \\
\hline
\end{tabular}


Formatif: Jurnal Ilmiah Pendidikan MIPA

Vol. 8, No. 1, April 2018, pp. 7-16

p-ISSN: 2088-351X

e-ISSN: 2502-5457

DOI: http://dx.doi.org/10.30998/formatif.v8i1.2303

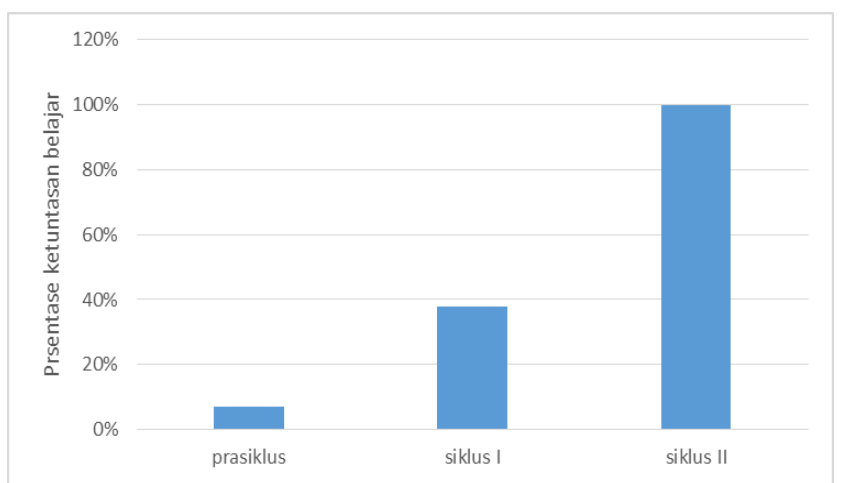

Gambar 3. Perbandingan ketuntasan belajar siswa

Dari gambar, menunjukkan bahwa prestasi belajar siswa mengalami peningkatan yang signifikan dari sebelum tindakan sampai dilakukan tindakan penelitian pada siklus II. Hal tersebut dibuktikan dengan persentase ketuntasan belajar siswa yaitu pra siklus ke siklus 1 terjadi peningkatan $31 \%$, peningkatan dari siklus I ke siklus II sebesar 62\%, dan peningkatan dari prasiklus sampai ke siklus II sebesar $93 \%$.

\section{Pembahasan}

Penelitian ini dilaksanakan pada dua siklus. Pada siklus I pertemuan pertama guru terlebih dahulu menjelaskan tujuan pembelajaran pada sub pokok bahasan sifatsifat cahaya, kemudian guru membagi siswa dalam lima kelompok. Satu kelompok terdiri dari enam siswa. Pembagian kelompok siswa berdasarkan nomor urut atau absen agar tidak terjadi kesenjangan anar siswa. Guru memberikan permasalahan (soal) dengan Edmodo, kemudian siswa melakukan prediksi penyelesaian masalah terhadap suatu peristiwa cahaya. Salah satu permasalahan yang diberikan guru contohnya "Jika senter dinyalakan dan dipantulkan terhadap kertas apa yang akan terjadi?". Setiap kelompok diberikan permaslaahan yang berbeda-beda. Siswa berdiskusi dalam kelompoknya masing-masing dengan e-learning di edmodo (note) terkait prediksi solusi awal tentang permasalahan (soal) yang diberikan oleh guru, sekaligus guru memberikan pretest dalam penelitian ini. Pada kegiatan explain ini dilakukan secara tatap muka, siswa mengemukakan pendapat kelompok berdasarkan diskusi kelompok pertama di Edmodo. Kemudian siswa melakukan praktikum di laboratorium sesuai dengan permasalahan yang diberikan oleh guru untuk mengamati kemungkinan-kemungkinan kejadian yang mungkin bisa digunakan dalam menganalisis dan mengambil kesimpulan. Guru membimbing siswa untuk membuat pengamatan yang relevan dengan konsep yang tepat. Langkah selanjutnya siswa mendiskusikan hasil praktikum bersama teman sekelompoknya dilakukan dengan tatap muka di kelas. Kemudian setelah itu siswa beserta kelompoknya menjelaskan hasil pengamatannya secara tatap muka dengan presentasi dan tanya jawab. Di akhir pertemuan guru memberikan kesimpulan dan penguatan terhadap materi.

Pada pertemuan kedua, guru menerapkan model pembelajaran yang sama seperti siklus I pertemuan pertama. Pada pertemuan kedua guru memberikan permasalahan mengenai cermin datar. Prediksi tersebut antara lain: "jika kita bercermin pada cermin rias bayangan apa yang nampak pada cermin?". Kemudian siswa menanggapi prediksi tersebut dan mendiskusikan dengan teman sekelompoknya secara online. Kemudian setelah itu siswa menjelaskan hasil prediksinya secara tatap muka di kelas. jawaban prediksi siswa beraneka ragam. Untuk membuktikan prediksi tersebut 
Formatif: Jurnal Ilmiah Pendidikan MIPA

Vol. 8, No. 1, April 2018, pp. 7-16

p-ISSN: 2088-351X

e-ISSN: $2502-5457$

DOI: http://dx.doi.org/10.30998/formatif.v8i1.2303

lagkah selanjutnya adalah melakukan pengamatan atau praktikum. Siswa mengamati kemungkinan-kemungkinan yang terjadi sesuai dengan prediksi. Setelah melakukan pengamatan kemudian siswa mendiskusikan hasil pengamatan dan melakukan analisis untuk mencari tahu jawaban yang sebenarnya. Akhirnya siswa memperoleh jawaban dari hasil pengamatan yang dilakukan dengan menjelaskan di depan kelas dengan presentasi tiap-tiap kelompok. Guru menanggapi presentasi siswa dan memberikan penguatan terhadap materi.

Setelah dilaksanakan tindakan pada siklus I kemudian siswa diberikan evaluasi (postest), untuk mengetahui pemahaman siswa pada materi cahaya dengan penerapan blended learning dengan aplikasi edmodo berbasis strategi pembelajaran PDEODE. Dari 29 siswa, sebanyak 11 siswa yang memperoleh nilai $\geq 75$ (tuntas KKM), sedangkan sisanya 18 siswa masih jauh dari KKM. Persentase ketuntasan belajar siswa 38\%, sehingga dilakukan refleksi untuk dilanjutkan tindakan lagi pada siklus II.

Siklus II dilaksanakan dalam dua pertemuan. Pada pertemuan pertama guru memberikan prediksi tentang materi cermin cekung dan cermin cembung. Prediksi tersebut antara lain "jika benda diletakkan pada ruang II maka bayangan yang terbentuk bagaimana?". Siswa mengerjakan prediksi dan mendiskusikannya dengan teman sekelompok secara online menggunakan aplikasi edmodo. Kemudian setelah itu siswa menjelaskan prediksi, berdasarkan hasil diskusi pertama dengan edmodo. Untuk membuktikan prediksi tersebut, siswa melakukan pengamatan pada cermin dan lensa. Siswa mendiskusikan hasil pengamatan untuk mendapatkan kesimpulan yang tepat berdasarkan analisis data pengamatan. Setelah itu siswa menjelaskan hasil pengamatan di depan kelas secara berkelompok, sedangkan keompok yang lain menanggapinya. Guru memberikan penguatan terhadap kesimpulan siswa. Di akhir pertemuan guru memberikan evaluasi untuk mengetahui sejauh mana pemahaman siswa mengenai materi cahaya.

Pada pertemuan kedua siklus II guru memberikan prediksi atau permasalahan mengenai lensa. Seperti biasa siswa menjawab hasil prediksi secara online yang sebelumnya harus didiskusikan dengan teman sekelompoknya. Kemudian secara tatap muka tiap kelompok menjelaskan jawaban hasil prediksi. Karena siswa penasaran dengan hasil prediksi, maka untuk membuktikannya siswa melakukan pengamatan terhadap peristiwa mengenai masalah tersebut. Setelah melakukan pengamatan siswa mendiskkusikan analisis dan hasil pengamatan tersebut dengan teman sekelompoknya, untuk mengetahui jawaban yang pasti dari hasil prediksi, apakah jawaban tersebut benar atau tidak. Kemudian guru membimbing siswa untuk menjelaskan hasil pengamatan dengan presentasi di depan kelas. Guru menjelaskan kesimpulan dan penguatan terhadap materi.

Setelah dilaksanakan tindakan pada siklus II dengan penerapan blended learning dengan aplikasi edmodo berbasis strategi pembelajaran PDEODE menunjukkan adanya peningkatan nilai evaluasi dari siklus I ke siklus II. Dapat dilihat dari peningkatan ketuntasan klasikal pada siklus II sebesar $100 \%$. Ini menunjukkan bahwa semua siswa mendapatkan nilai di atas KKM. Nilai rata-rata prestasi belajar siswa juga meningkat pada siklus II yaitu sebesar 88 .

Untuk melihat peningkatan prestasi belajar siswa dilihat dari analisis nilai ratarata pretest dan postest berdasarkan rumus Gain Standar . nilai prestasi belajar siswa yang dibandingkan adalah nilai sebelum tindakan dan nilai evaluasi pada siklus II. Dengan rumus Gain Standar diperoleh nilainya sebesar 0,77 dengan kategori "tinggi”. Ini menunjukkan bahwa terjadi peningkatan yang signifikan prestasi belajar siswa dari sebelum tindakan sampai pada setelah tindakan pada siklus II. Proses pembelajaran fisika yang digabungkan atau secara blended learning antara strategi pembelajaran PDEODE dan aplikasi edmodo berdampak positif terhadap jalannya pembelajaran. siswa terlihat 
Formatif: Jurnal Ilmiah Pendidikan MIPA

Vol. 8, No. 1, April 2018, pp. 7-16

p-ISSN: 2088-351X

e-ISSN: $2502-5457$

DOI: http://dx.doi.org/10.30998/formatif.v8i1.2303

antusias dalam pembelajarannya, terlihat pada motivasi belajar siswa juga meningkat. Siswa menjadi aktif baik dalam bertanya, psikomotorik, dan afektifnya.

Sejalan dengan pendapatnya Suriadhi et al (2014) terdapat perbedaan yang signifikan hasil belajar bahasa IPA siswa antara sebelum dan sesudah menggunakan $e$ learning berbasis Edmodo. Nilai rata-rata setelah menggunakan media $(89,03)$ lebih tinggi dibandingkan sebelum menggunakan media $(58,26)$. Dengan menggunakan Edmodo dapat meningkatkan keaktifan siswa di kelas juga. Edmodo dapat melanjutkan diskusi kelas online, memberikan polling untuk memeriksa pemahaman siswa, dan lencana penghargaan kepada siswa secara individual berdasarkan kinerja atau perilaku.

Blended learning membuat siswa menjadi menyenangkan dan mengurangi kejenuhant. antusias siswa terhadap proses pembelajaran blended learning sehingga akan menambah motivasi siswa untuk belajar dan mempermudah dalam memahami materi pembelajaran (Rizkiyah, 2015). Dalam implementasi kurikulum, blended learning sangat berpotensi menciptakan pengalaman bagi siswa karena membantu merepresentasikan keuntungan yang jelas untuk dapat menciptakan pengalaman belajar tersebut (Bentri et al, 2014). Pengalaman yang diperoleh siswa dapat memberikan pengetahuan, keterampilan dan kompetensi bagi siswa itu sendiri. Tanpa memperhatikan jarak dan waktu, blended learning dapat menjadi salah satu cara untuk mencapai tujuan yang diharapkan.

Pembelajaran PDEODE dapat memungkinkan siswa membangkitkan rasa ingin tahu terhadap suatu masalah, dan mengaitkannya pada fenomena nyata (Nurmayanti et al, 2015). Strategi pembelajaran PDEODE mampu melatih siswa untuk membangun konsepkonsep yang ilmiah karena siswa dapat berfikir mandiri, siswa aktif berbicara atau menulis, secara interaktif mengkomunikasikan buah pikiran kepada siswa yang lain melakukan dan mengamati percobaan secara langsung, mengklarifikasi, mempertahankan, mengembangkan, dan menjelaskan pikiran siswa (Sa'idah \& Suyono, 2012). Pembelajaran ini membangun pengetahuan siswa dengan membuat hubungan makna antara konsep baru yang diperoleh dengan pengetahuan yang dimiliki siswa.

Dengan adanya pembelajaran yang dapat mengaktifkan siswa dengan metode PDEODE dipadukan dengan pembelajaran secara online (blended learning) dengan aplikasi edmodo merupakan suatu inovai baru dalam pembelajaran sehingga dapat meningkatkan prestasi belajar. Aktivitas siswa dan psikomotrosik siswa juga meningkat, siswa merasakan suasana baru dalam pembelajaran.

\section{PENUTUP}

Berdasarkan hasil dan pembahasan pada penelitian yang telah diuraikan, maka dapat diperoleh kesimpulan bahwa penerapan blended learning dengan aplikasi edmodo berbasis strategi pembelajaran PDEODE dapat meningkatkan prestasi belajar siswa kelas VIIIF MTs N Magelang. Hal tersebut dibuktikan dengan persentase ketuntasan belajar siswa yaitu prasiklus ke siklus 1 terjadi peningkatan $31 \%$, peningkatan dari siklus I ke siklus II sebesar $62 \%$, dan peningkatan dari prasiklus sampai ke siklus II sebesar $93 \%$.

Peneliti menghadapi beberapa kendala dalam proses pembelajaran dikelas selama penelitian berlangsung. Oleh karena itu peneliti memberi beberapa saran untuk mengatasi kendala tersebut. Pertama, penerapan blended learning dengan aplikasi edmodo akan lebih baik jika fasilitas-fasilitas sekolah mendukung kegiatan pembelajaran. Kedua, siswa terlebih dahulu diperkenalkan dengan dunia internet agar pada saat pembelajaran dengan blended learning siswa tidak akan kebingungan dalam aplikasinya. Ketiga, penggunaan waktu untuk penerapan strategi pembelajaran PDEODE perlu diperhatikan sehingga pembelajaran dapat berjalan dengan baik. Keempat, penerapan blended learning dengan 


\section{Formatif: Jurnal Ilmiah Pendidikan MIPA}

Vol. 8, No. 1, April 2018, pp. 7-16

p-ISSN: 2088-351X

e-ISSN: 2502-5457

DOI: http://dx.doi.org/10.30998/formatif.v8i1.2303

aplikasi edmodo berbasis strategi pembelajaran PDEODE dapat dijadikan sebagai salah satu strategi pembelajaran alternatif di sekolah untuk meningkatkan prestasi belajar siswa.

\section{DAFTAR PUSTAKA}

Ainiyah, Z., \& Puspasari, D. (2015). Penggunaan edmodo sebagai media pembelajaran elearning pada mata pelajaran otomatisasi perkantoran di SMKN 1 Surabaya. Jurnal Administrasi Perkantoran (JPAP), 3(3).

Arikunto, S. (2006). Prosedur Penelitian Suatu Pendekatan Praktek. Jakarta : Rineka Cipta.

Bentri, A., Zen, Z., \& Rahmi, U. (2014). Formulasi strategi penerapan blended learning dalam implementasi kurikulum di jurusan KTP FIP Universitas Negeri Padang. Penelitian Pendidikan, 5(1).

Dharmawati. (2017). Penggunaan media e-learning berbasis edmodo dalam pembelajaran english for business. QUERY: Jurnal Sistem Informasi, 1(1), 43-49.

Nurmayanti, F., Bakri, F., \& Budi, E. (2015). Pengembangan Modul Elektronik Fisika dengan Strategi PDEODE pada Pokok Bahasan Teori Kinetik Gas untuk Siswa Kelas XI SMA. Prosiding Simposium Nasional Inovasi dan Pembelajaran Sains.

Rizkiyah, A. (2015). Penerapan blended learning untuk meningkatkan hasil belajar siswa pada mata pelajaran ilmu bangunan di kelas X TGB SMK Negeri 7 Surabaya. Jurnal Kajian Pendidikan Teknik Bangunan, 1(1).

Sa'idah, G., \& Suyono. (2012). Penerapan Strategi Pembelajaran PDEODE (Predict, Discuss, Explain, Observe, Discuss, Explain) untuk Mereduksi Miskonsepsi Siswa pada Materi Pokok Hidrolisis Garam di SMAN 2 Bojonegoro. In Prosiding Seminar Nasional Kimia Unesa.

Sari, A. R. (2013). Strategi blended learning untuk peningkatan kemandirian belajar dan kemampuan critical thinking mahasiswa di era digital. Jurnal Pendidikan Akuntansi Indonesia, 11(2).

Sugiyono. (2007). Statistika untuk Penelitian. Bandung : Alfabeta.

Suriadhi, G., Tastra, I. D. K., \& Suwatra, I. I. W. (2014). Pengembangan e-learning berbasis edmodo pada mata pelajaran IPA kelas VIII di SMP Negeri 2 Singaraja. Jurnal Edutech Undiksha, 2(1).

Warso, Agus Wasisto Dwi Doso. (2013). Publikasi Ilmiah Penelitian Tindakan Kelas. Yogyakarta: Graha Cendekia.

Wulandari, R. R., Siswoyo, S., \& Bakri, F. (2015). Pengaruh Model Pembelajaran PDEODE terhadap Hasil Belajar Kognitif Fisika Siswa SMA. In PROSIDING SEMINAR NASIONAL FISIKA (E-JOURNAL) (Vol. 4, pp. SNF2015-I). 
Formatif: Jurnal Ilmiah Pendidikan MIPA

Vol. 8, No. 1, April 2018, pp. 7-16

p-ISSN: 2088-351X

e-ISSN: 2502-5457

DOI: http://dx.doi.org/10.30998/formatif.v8i1.2303 